\title{
The effect of alcohol on resting metabolic rate
}

\author{
BY KATHRYN ROSENBERG AND J. V. G. A. DURNIN \\ Institute of Physiology, University of Glasgow, Glasgow Gi2 8QQ, Scotland
}

(Received 5 November 1976 - Accepted 16 January 1978)

1. There was a significant increase in oxygen consumption in ten women after small intakes of alcohol.

2. No significant difference was found between the average increase in metabolic rate over $3 \mathrm{~h}$ after an isoenergetic meal of food or of food plus alcohol. However, during the last half of the $3 \mathrm{~h}$ postprandial period, the increased $\mathrm{O}_{2}$ consumption was significantly greater after the meal including alcohol.

3. Possible explanations for the contradictory results in the literature are discussed.

Although there is no precise information, alcohol must often provide from 10 to $30 \%$ of the daily energy intake for many adults. Yet, in spite of its nutritional importance, and the fact that it is often implicated in obesity, we do not know even such a basic fact as whether or not it has an effect on the resting metabolic rate (RMR), the so-called 'specific dynamic action'. This is not even mentioned in a well-known nutritional textbook (Davidson, Passmore, Brock \& Truswell, 1975). Much classical and modern work (Atwater \& Benedict, 1902; Higgins, 1917; Le Breton \& Trémolières, 1955; Barnes, Cooke, King \& Passmore, I965; Williams, 1972) suggests that alcohol does not increase the metabolic rate. On the other hand, increases in metabolic rate after ingestion of alcohol have been measured in both mice and rats (Perman, 196I, 1962a; Kalant, Hawkins \& Watkin, 1963; Shrimpton, 1972) and in man (Nagamine, Tezuka, Yamakawa \& Suzuki, I96I; Perman, 1962b).

The amount of alcohol given in these experiments has usually been very small. Therefore, methodological errors may frequently be responsible for the conflicting opinions of the various authors. The present investigation attempted to clarify the uncertainty related to the influence of alcohol. In addition, possible interactions between food and alcohol on the RMR (as suggested recently by Stock, Stock \& Stuart, 1973; Stock \& Stuart, 1974) were investigated.

\section{METHODS}

There were two parts to the present study. In the first study it was considered that the careful measurement of the RMR was of prime importance in setting as uniform as possible a base-line against which the metabolic rate after alcohol or meals or both could be assessed. Therefore, the subjects chosen for this experiment were either very experienced in the use of the apparatus or were yoga practitioners. Ten women took part. Their ages, heights and weights are given in Table I. All were moderate 'social drinkers' with the exception of one woman who was an abstainer.

The experimental routine was as follows: the subject came to the laboratory after an overnight fast and rested in a comfortable reclining armchair for $30 \mathrm{~min}$. When each woman had become adequately accustomed to the wearing of the equipment and had breathed through a mouthpiece or mask in a relaxed fashion for some minutes, three $5 \mathrm{~min}$ measurements of resting oxygen consumption were made at $15 \mathrm{~min}$ intervals. Expired air was collected in Douglas bags and analysed for $\mathrm{O}_{2}$ and carbon dioxide contents $(\%)$ using paramagnetic (Servomex Oxygen Analyzer, Type OA IOI; Servomex Controls Ltd, Crowborough, Sussex) and infra-red (MSA LIRA model 300; Mine Safety Appliances 
Table I. Physical characteristics of the subjects

\begin{tabular}{|c|c|c|c|}
\hline Subject no. & Age & $\begin{array}{l}\text { Height } \\
\text { (m) }\end{array}$ & $\begin{array}{l}\mathrm{Wt} \\
(\mathrm{kg})\end{array}$ \\
\hline \multicolumn{4}{|c|}{ Women } \\
\hline $\mathbf{I}$ & $2 \mathrm{I}$ & $I .65$ & 55.9 \\
\hline 2 & 35 & $1 \cdot 65$ & $55^{\circ} 0$ \\
\hline 3 & 29 & $1 \cdot 64$ & 51.0 \\
\hline 4 & 30 & $1 \cdot 75$ & $60 \cdot 0$ \\
\hline 5 & 37 & $I \cdot 56$ & $72 \cdot 9$ \\
\hline 6 & 37 & $I \cdot 64$ & $55 \%$ \\
\hline 7 & 30 & 1.66 & 53.9 \\
\hline 8 & 33 & 1.60 & $59 \cdot 5$ \\
\hline 9 & 29 & $I \cdot 78$ & 63.0 \\
\hline 10 & 21 & $I \cdot 66$ & 78.9 \\
\hline Mean & 30 & 1.66 & 60.5 \\
\hline SD & 5.4 & $0.06 \mathrm{I}$ & 8.4 \\
\hline \multicolumn{4}{|c|}{ Men } \\
\hline I & 33 & $\mathrm{I} \cdot 82$ & $70 \cdot 5$ \\
\hline 2 & $3 \mathrm{I}$ & $1 \cdot 85$ & $81 \cdot 5$ \\
\hline 3 & 40 & $I \cdot 74$ & 73.5 \\
\hline 4 & 27 & $1 \cdot 73$ & 65.9 \\
\hline 5 & 28 & 1.90 & $83 \cdot 1$ \\
\hline Mean & 32 & $\mathrm{I} \cdot 8 \mathrm{I}$ & $74 \cdot 9$ \\
\hline SD & $4 \cdot 6$ & 0.066 & 6.5 \\
\hline
\end{tabular}

Co. Ltd, Glasgow) analysers. The analysers were calibrated using guaranteed cylinders of standard gas mixtures (British Oxygen Co., Deer Park Lane, London SW I9).

After the three RMR measurements had been made, each woman was then given one of three types of meal, which had to be consumed within ro min. One type of meal was given on each of three successive days and the order varied between subjects. Meal no. I was $230 \mathrm{ml}$ red table wine (approximately $630 \mathrm{~kJ}$ ( $150 \mathrm{kcal})$ ), chosen because it is a common form in which alcohol is consumed and is a dosage ( $0.3-0.4 \mathrm{~g}$ ethanol $/ \mathrm{kg}$ body-weight) comparable to that in other published work. Meal no. 2 consisted of ham sandwiches with an energy content of $2500 \mathrm{~kJ}$ (approximately $600 \mathrm{kcal}$ ) ( $15 \%$ was protein energy, the remainder of the energy being equally divided between fat and carbohydrate), together with $230 \mathrm{ml}$ red wine. Meal no. 3 was also made up of ham sandwiches $(2500 \mathrm{~kJ})$ but with a fruit drink which was similar in appearance and quantity and isoenergetic with the wine. A fourth 'meal' of $230 \mathrm{ml}$ of water, was given to four subjects only.

After consuming one of these meals, the $\mathrm{O}_{2}$ consumption of each woman was measured during $5 \mathrm{~min}$ periods at $\mathrm{I} 5 \mathrm{~min}$ intervals for the ensuing $3 \mathrm{~h}$, while they remained reclining in the armchair.

In the second experiment, an attempt was made to have a more realistic comparison between alcohol and food by making the 'meals' isoenergetic, and by increasing the quantity of alcohol to levels where the energy intake, if it were in the form of food, might be expected to be large enough to show a metabolic effect.

Five men acted as subjects. They were not selected, as were the women in the first experiment, in order to minimize variability in RMR but rather because of their willingness to consume the dose of alcohol. Table I also gives the ages, heights and weights of these men. Measurements were done on each man in the post-absorptive relaxed state as in the case of the women. However, eight measurements of RMR were made during $2 \mathrm{~h}$ before the meal and eight measurements after the meal. The longer duration and greater number of preprandial measurements provided more information on the variability of replicate measure- 


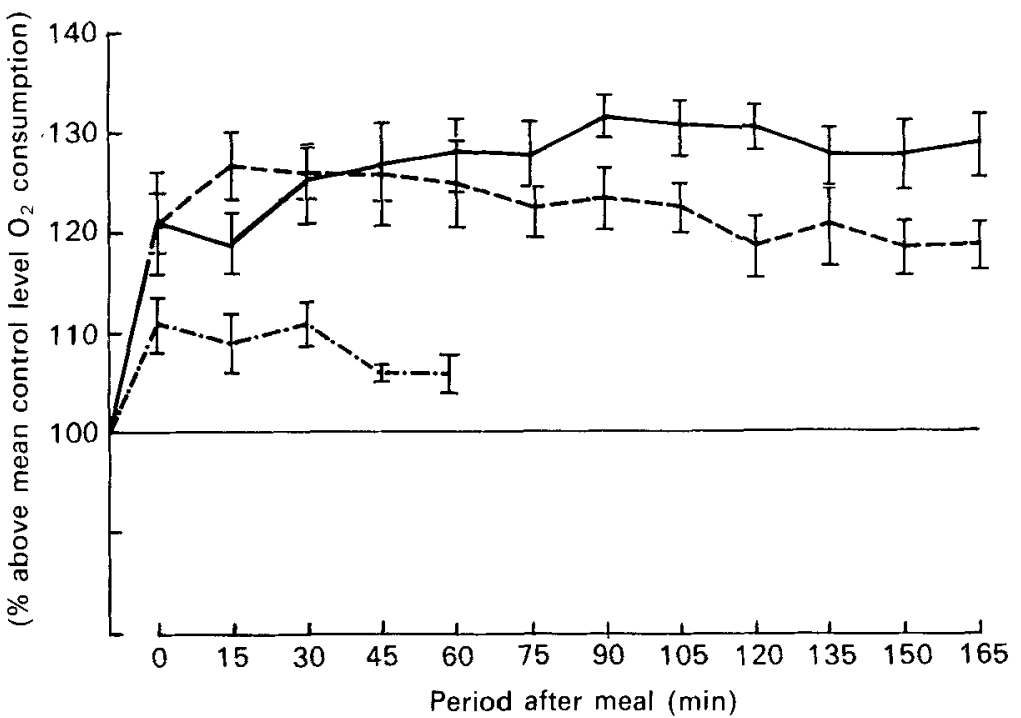

Fig. I. Mean increase in resting oxygen consumption ( $\%$ above mean control levels) of ten women after 'meals' of: alcohol alone, (- - - $)$; food alone, (-- ); food plus alcohol, ( -$)$. For details of 'meals' see p. 294, and for details of subjects, see p. 293 and Table I. Vertical bars represent the estimated standard errors of the means.

ments of RMR. Two 'meals' were given: one consisted of ham sandwiches similar to those in the first experiment, but with a reduced energy content of $1250 \mathrm{~kJ}(300 \mathrm{kcal})$, whereas the second consisted of $\mathrm{I} 18 \mathrm{ml}$ vodka ( $80 \%$ proof) diluted to taste with water or dietetic lemonade and also with an energy content of $I 250 \mathrm{~kJ}$.

The statistical procedure used in the analysis of the results from the first experiment on the ten women was the 'sign' test (Bahn, 1972). For the second experiment on the five men, the mean of each subject's $\mathrm{O}_{2}$ consumption before each meal was compared to the corresponding mean after each meal by the $t$ test.

\section{RESULTS AND DISCUSSION}

The four subjects who were given water to drink all showed a slight increase in $\mathrm{O}_{2}$ consumption during the first measurement which, in all cases, decreased to control values by the second measurement (presumably an effect due to temporary disturbance of the subject). Therefore, in the main experiment the first postprandial measurement was not taken into account in the statistical analysis of the results.

As an indication of the variation in the control values of $\mathrm{O}_{2}$ consumption for the ten women, the average coefficients of variation for the $\mathrm{O}_{2}$ consumption during the base-line period were 4 (alcohol) and 5 (alcohol plus food, and food). The mean $\mathrm{O}_{2}$ consumption for the ten women for the control period was $192 \mathrm{ml} / \mathrm{min}$ (wine, and food plus wine) and $198 \mathrm{ml} / \mathrm{min}$ (food alone). For statistical and graphical purposes, the $\mathrm{O}_{2}$ consumption at each point after a ' meal' was compared for each woman with her mean control value. The values were thus used in the form of before and after pairs of values for each subject.

All ten women showed a higher $\mathrm{O}_{2}$ consumption during the first hour after taking the alcohol compared to their individual mean value beforehand. Although there was considerable variability among the ten individuals in the size of the increase in metabolic rate, it is the consistency of the increase which is responsible for the high significance $(P<0.001)$. On average, the increase in $\mathrm{O}_{2}$ uptake for the ten women after the alcohol was $8 \%$. 
Table 2. Oxygen consumption before and after a 'meal' of energy content $1250 \mathrm{~kJ}$ given either as food or alcohol* in five male subjects $\dagger$

\begin{tabular}{|c|c|c|c|c|c|c|}
\hline \multirow{3}{*}{$\begin{array}{l}\text { 'Meal' given as } \\
\text { Subject no. }\end{array}$} & \multicolumn{6}{|c|}{$\mathrm{O}_{2}$ uptake $(\mathrm{ml} / \mathrm{min})$} \\
\hline & \multicolumn{2}{|c|}{ Food } & \multirow{2}{*}{$\begin{array}{l}\text { Statistical } \\
\text { significance of } \\
\text { difference: } P\end{array}$} & \multicolumn{2}{|c|}{ Alcohol } & \multirow{2}{*}{$\begin{array}{l}\text { Statistical } \\
\text { significance of } \\
\text { difference: } P\end{array}$} \\
\hline & Before & After & & Before & After & \\
\hline 1 & 252 & 282 & $<0.0 \mathrm{I}$ & 264 & 285 & $<0.05$ \\
\hline 2 & 245 & 278 & $<0.001$ & 233 & 247 & $<0.01$ \\
\hline 3 & 236 & 246 & NS & 224 & 223 & NS \\
\hline 4 & 233 & 249 & $<0.01$ & 233 & 244 & NS \\
\hline 5 & 273 & 286 & NS & 302 & 302 & NS \\
\hline \multicolumn{7}{|c|}{$\begin{array}{l}\text { NS, not significant. } \\
\text { * For details, see p. } 294 . \\
\dagger \text { For details, see p. } 293\end{array}$} \\
\hline
\end{tabular}

Observations were discontinued after the first hour because, although some women still showed a small increase in metabolic rate, most of them had returned to their normal resting value. This effect of alcohol on the metabolic rate of the women is illustrated in Fig. I. Each point is the mean increase $(\%)$ of the ten women.

As expected, there was also a highly significant increase $(P<0.001)$ in metabolic rate after the meals both of food, and of food with alcohol. Over the whole postprandial period, no significant difference could be detected between the size of the increase observed after the meal of food alone and the meal of food and alcohol: in three of the ten subjects there was a greater increase in metabolic rate after the meal of food alone and in the remaining seven subjects there was a greater mean increase over the $3 \mathrm{~h}$ after the meal of food and alcohol. However, during the second $\mathrm{I} \cdot 5 \mathrm{~h}$ of the postprandial period the average increase in metabolic rate for each. subject for the meal of food plus alcohol was greater in nine of the ten subjects than after the meal of food alone. This greater metabolic rate after the meal with alcohol for the final $\mathrm{I} \cdot 5 \mathrm{~h}$ was significant $(P<0.0 \mathrm{I})$. The over-all average increase in metabolic rate for the ten women after the food meal was $23 \%$ and for the food plus alcohol it was $27 \%$. Stock et al. (1973) and Stock \& Stuart (1974), suggested that alcohol in some way potentiated the increase in metabolic rate occurring after food. Our results do not directly confirm their results but the greater increase in metabolic rate after food and alcohol during the second $\mathrm{I} \cdot 5 \mathrm{~h}$ postprandially which we observed may suggest a longer duration of the effect after a meal with alcohol.

These results confirm the view that alcohol causes an increase in metabolic rate. There are several factors which may have contributed to the contradictory results in the literature. One of the most obvious features of RMR is the considerable variability in this measurement within individuals. This fact has been discussed in the classical 'basal metabolic rate' (BMR) literature (Berkson \& Boothby, 1938) and more recently (Durnin, Rahaman \& Ferro Luzzi, 1966; Garrow \& Hawes, 1972). Its existence means that any factor which is exerting only a small influence on metabolic rate will be difficult to detect, and this has surely been largely responsible for the confused interpretation of the metabolic effects of alcohol. Moreover, the amounts of alcohol used in most of the previously-published work have been small enough to make any effect easily concealed by the background variability. These amounts have ranged from $0.18 \mathrm{~g} / \mathrm{kg}$ body-weight (Atwater \& Benedict, 1902) to $0.7 \mathrm{~g} / \mathrm{k}$ body-weight (Williams, I972), which, standardized for a $65 \mathrm{~kg}$ man, represent a range of approximately $340-\mathrm{I} 300 \mathrm{~kJ}(80-320 \mathrm{kcal})$. These are small quantities of energy compared to those provided in food for similar experimental purposes. Most investigators have given 


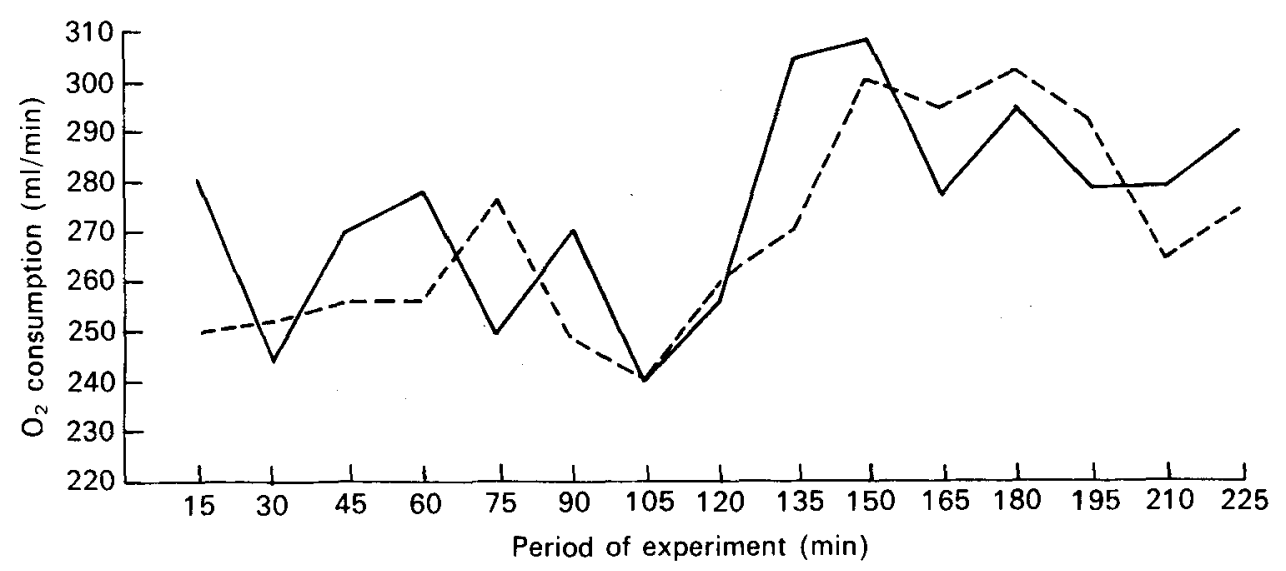

Fig. 2. Resting oxygen consumption $(\mathrm{ml} / \mathrm{min})$ before and after a 'meal' of either alcohol (-) or food (--) by subject no. I. For details of 'meal', see p. 294, and for details of subject, see p. 293 and Table 1. $\uparrow, 1250 \mathrm{~kJ}$ (300 kcal) alcohol or food given).

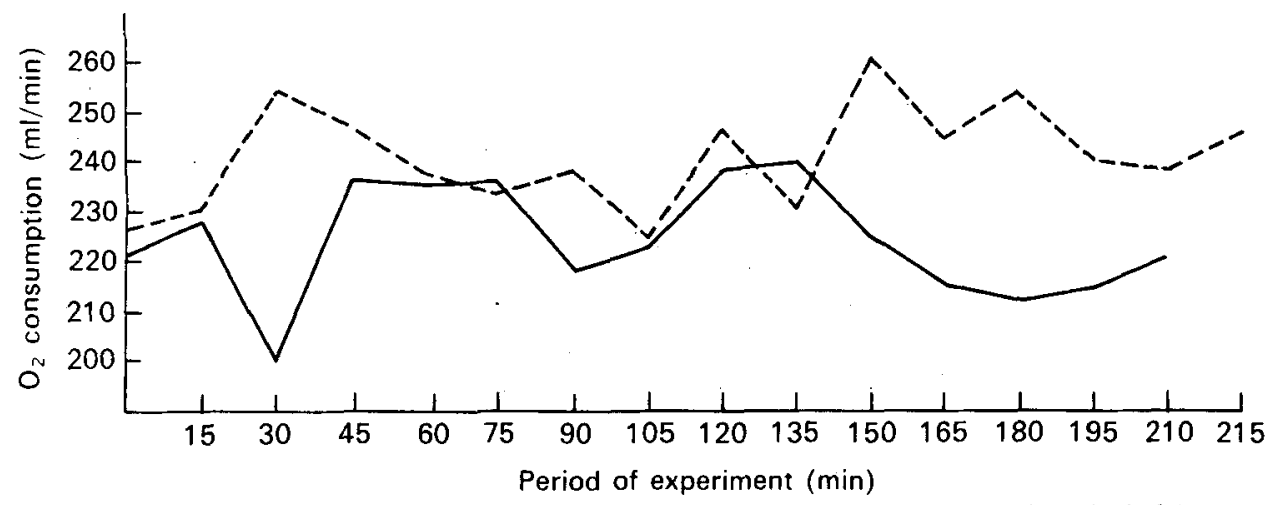

Fig. 3. Resting oxygen consumption $(\mathrm{ml} / \mathrm{min})$ before and after a 'meal' of either alcohol (- - ) or food (--) by subject no. 3. For details of 'meal', see p. 294, and for details of subjects, see p. 293 and Table $\mathrm{I}$. $\uparrow, 1250 \mathrm{~kJ}$ ( $300 \mathrm{kcal})$ alcohol or food given.

alcohol with an energy value of approximately $830 \mathrm{~kJ}(200 \mathrm{kcal})$ whereas much classical work on 'specific dynamic action' of foods (cf. Du Bois, 1927) had meals containing more than $4000 \mathrm{~kJ}$ and none were as low as $800 \mathrm{~kJ}$. Experiments, therefore, which have attempted to measure change in metabolic rate after alcohol have had two major difficulties. First, there is the problem of the high variability of the BMR. Secondly, there is the problem of looking for small changes as a consequence of low dosages. We attempted to deal with the first problem in the first part of this experiment through selection of subjects. We attempted to deal with the second problem in the second part of the experiment by giving a larger quantity of alcohol with an energy content more comparable to that of food given in similar experiments. In addition, eight measurements of RMR were made over $2 \mathrm{~h}$ in the five men acting as subjects to illustrate better base-line variability. The energy content of the alcohol and food meals was $1250 \mathrm{~kJ}$. This amount seemed near the limit as far as the intoxicating effects of alcohol and the subject's ability to drink this quantity in a short time were concerned.

Table 2 gives the average $\mathrm{O}_{2}$ consumption before and after each of the two meals for the five subjects and the significance values for the difference between the means. Two subjects 


\section{Kathryn Rosenberg and J. V. G. A. Durnin}

responded to both alcohol and food with a significant increase in their $\mathrm{O}_{2}$ consumption. Two subjects showed no significant increase to either of the meals and one subject showed a significant increase to food but not to alcohol. Fig. 2 illustrates the changes in $\mathrm{O}_{2}$ consumption before and after both meals in one of the two subjects showing a significant increase to both. Fig. 3 illustrates the case of one of the subjects who showed neither a significant increase to food (known to cause an increase in metabolic rate) nor to a meal of alcohol.

From these results we would suggest that at low energy intakes changes in metabolic rate are difficult to demonstrate in individuals with variable RMR values. This difficulty applies both to experiments involving the administration of food (known to cause an increase in metabolic rate) and to experients where the source of energy is alcohol. The broadly comparable response in these five men to intakes of energy either in the form of alcohol or food suggests that the so-called 'specific dynamic action' may be a function of energy intake, independent of nutrient intake. This has been suggested elsewhere (Garrow \& Hawes, I972; Pittet, Gygax \& Jéquier, 1974) and, in this context, the effects of alcohol, fats, carbohydrates, and proteins may all be similar.

The authors are grateful to Scottish and Newcastle Breweries Ltd for supplying the wine and spirits, and are indebted to the subjects and to $\mathrm{Mr} \mathrm{R}$. Campbell for much technical assistance, and to Mr D. McLaren, Senior Lecturer in Statistics at the University of Glasgow, for his advice on statistical procedures. K. R. was in receipt of a Medical Research Council Studentship at the time of this investigation.

\section{REFERENCES}

Atwater, W. O. \& Benedict, F. G. (1902). Mem. natn. Acad. Sci. no. 6, VIII.

Bahn, A. K. (1972). Basic Medical Statistics, p. 178. New York and London: Grune and Stratten.

Barnes, E. W., Cooke, N. J., King, A. J. \& Passmore, R. (I965). Br. J. Nutr. 19, 485.

Berkson, J. \& Boothby, W. M. (1938). Am. J. Physiol. 12r, 669.

Davidson, S., Passmore, R., Brock, J. F. \& Truswell, A. S. (1975). Human Nutrition and Dietetics, 6th ed., p. 91, Edinburgh: Churchill Livingstone.

Du Bois, E. F. (1927). Basal Metabolism in Health and Disease, 2nd ed., pp. 50-I. Philadelphia: Lea and Febiger.

Durnin, J. V. G. A., Rahaman, M. M. \& Ferro-Luzzi, A. (I966). Proc. Nutr. Soc. 25, xv.

Garrow, J. S. \& Hawes, S. F. (1972). Br. J. Nutr. 27, 211.

Higgins, H. L. (1917). J. Pharmac. 9, 441.

Kalant, H., Hawkins, R. D. \& Watkin, G. S. (1963). Can. J. Biochem. Physiol. 41, 2197.

Le Breton, E. \& Trémolières, J. (1955). Proc. Nutr. Soc. 14, 97.

Nagamine, S., Tezuka, T., Yamakawa, K. \& Suzuki, S. (196I). Rep. natn. Inst. Nutr., Tokyo p. 7.

Perman, E. S. (I96I). Biochem. Pharmac. 8, 172.

Perman, E. S. (I962a). Acta physiol, scand. 55, 189.

Perman, E. S. (1962 b). Acta physiol. scand. 55, 207.

Pittet, Ph., Gygax, P.-H. \& Jéquier, E. (1974). Br. J. Nutr. 3x, 343.

Shrimpton, R. (1972). Proc. Nutr. Soc. 31, 35A.

Stock, A. L., Stock, M. J. \& Stuart, J. A. (1973). Proc. Nutr. Soc. 32, 40A.

Stock, M. J. \& Stuart, J. A. (1974). Nutr. Metab. 17, 297.

Williams, M. H. (1972). Res. Quart. 43, 94. 